\title{
Vibration - A tool for machine diagnostics and condition monitoring
}

\author{
K N GUPTA \\ Department of Mechanical Engineering, Indian Institute of Technology, \\ New Delhi 110016, India \\ Present address: Institute of Engineering \& Technology, Rohilkhand University, \\ Bareilly 243001 , India
}

\begin{abstract}
Vibration is an effective tool in detecting and diagnosing some of the incipient failures of machines and equipment. The present paper deals with the basic principles, which may help in identifying its diagnostic ability, the scope of its diagnostic capabilities, the instrumentation in vogue for its monitoring and the state-of-the-art of the monitoring techniques and programs. A few case studies are also given to illustrate how machine troubles/failures are diagnosed with the help of vibration signatures.
\end{abstract}

Keywords. Vibration analysis; vibration signatures; machine diagnostics; condition monitoring.

\section{Introduction}

The subject of vibration generally deals with methods to determine the vibration characteristics of a system, its vibratory response to a given excitation and the means to reduce the vibration. Reference is however hardly made to its diagnostic ability. A vibration signature measured on the external surface of a machine or a structure contains a good amount of information, which, if properly interpreted, can reveal the running condition of the machine. It may be regarded as one of the languages through which a machine tells us of its ailments. This information is useful in making suitable decisions regarding machine or plant maintenance. Attempts have been made for the last two decades to exploit this feature of vibration signature for the benefit of machine condition monitoring, and the result is a well proven technology now in vogue. This success has been possible due to the tremendous developments made by specialists in the areas of instrumentation, electronics and computers. Books by Collacott $(1973,1977)$ are often referred to, whenever a topic on condition monitoring and fault diagnosis is discussed. Articles by Gupta $(1986,1990)$ provide a lucid description of the state-of-the-art of the vibration monitoring technique.

Because of the diagnostic ability of vibration, its monitoring forms a part of 'Condition Based Maintenance (CBM)'. The concept of CBM is very fascinating. It indicates carrying 
out of maintenance, only when the condition of the equipment requires it as a safeguard from incipient failure. This strategy helps in reducing maintenance costs and chances of unscheduled breakdown or shutdown of the equipment. An improvement in productivity is inevitable. However, this requires sophisticated electronic instruments to monitor the condition of the equipment. Hence a knowledge of such instruments is essential.

Before a brief description of such instruments is given, it is thought appropriate to list the diagnostic capabilities of a vibration signature vis-a-vis machine ailments and to enunciate the basic principles involved, which may help in exploring further such capabilities. The present paper provides a glimpse of the state-of-the-art of this diagnostic technique and the possible future trends in its application to plant and machine maintenance. Some case studies are also included to illustrate how a fault could be diagnosed through vibration signatures.

\section{Basic principles involved}

The technique of condition monitoring through vibration is built up on the following principles

(1) Any malfunctioning or deterioration in the operation of a machine component gives rise to increase in vibration level.

(2) Vibration emanating from a component consists of certain frequencies depending upon its nature of operation. This frequency information does not get changed or lost during transmission of vibration, however, their vibration level may be attenuated.

(3) Mixing of different vibrations does not cause any loss of the individual's frequency information.

(4) Every individual component or system has its own frequency, called its natural frequency, which changes only when the system parameters get affected.

Figure 1 illustrates nicely some of the principles enunciated above. The unbalance in the coupling generates vibrations with frequency equal to the rotational speed, the bearing generates vibration of frequency depending on the number of balls and the gear

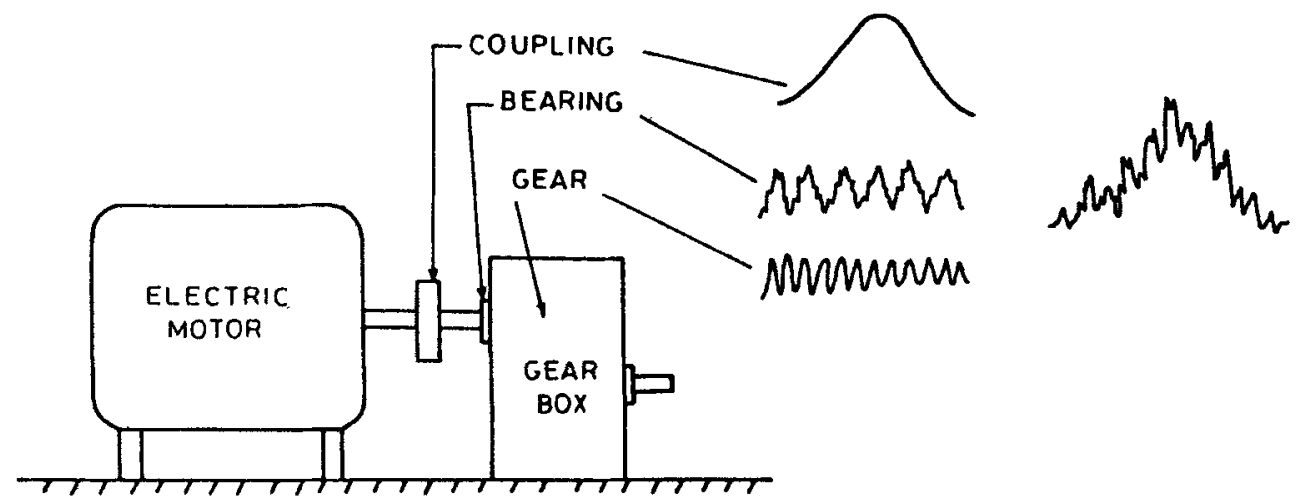

Figure 1. Vibration generation and transmission. 
generates vibrations of tooth-meshing frequency. These vibrations mix with each other during transmission, and the mixed signal is picked up by the transducer. The mixed signature has all the frequencies of the individual vibrations, i.e. no information with regard to frequency is lost in mixing or transmission.

\section{Diagnostic capabilities of a vibration signature}

A vibration signature taken from an appropriate location in a machine can reveal the presence of the following machine defects: Imbalance, misalignment, imperfect foundation, mechanical looseness, rubs, antifriction bearing defects, faults in belt drive, faults in gears, sleeve bearing looseness, oil whirl, blades/vanes defects, local resonances, etc.

In general, any machine defect, which alters the dynamic behaviour of the machine can be detected through a vibration signature.

\section{Instrumentation and diagnostic parameters}

For carrying out vibration monitoring, suitable instrumentation is required and, depending on the nature of the diagnosis, appropriate processing parameters, also called diagnostic parameters, should be identified. This section deals with these aspects of vibration monitoring.

Selection of proper instrumentation for vibration monitoring is an important feature. A vibration measuring system consists of a sensor or transducer, a signal processing unit and a display unit or recorder. The transducer is used to convert mechanical vibration into an electrical signal. The signal processing unit conditions, amplifies, integrates or differentiates and analyses the signal for its frequency spectrum. Finally, the display or recorder unit presents the vibration characteristics in an interpretable form.

The three vibration transducers generally used have the following practical measurement amplitude ranges:

- the proximity displacement transducer $100: 1$

- the velocity pickup $1000: 1$

- the piezoelectric accelerometer $\quad 30 \times 10^{6}: 1$

Thus, from this angle, the piezoelectric accelerometer should be the best choice. Further, it is lighter and has better frequency range for application. These days accelerometers are used as sensors in most vibration monitoring systems. Some instrument manufacturing firms, particularly Brüel \& Kjaer of Denmark, have developed a well-perfected technology for vibration monitoring with these sensors:

Proximity displacement transducers are generally used in case of rotating machines having their rotors mounted on oil bearings. Displacement probes, generally two in number at each bearing support, monitor the orbital motion of the rotor. It is the shape and nature of these orbital paths which provide the clues for impending defects in the rotor. Defects like imbalance, misalignment, oil/shaft whirl and rotor cracks are easily detected. M/s Bently, Nevada, USA are the pioneers in developing a technology with eddy current probes as transducers. The turbo-generator sets of many powerplants are equipped with these instruments. 
Table 1. Time-based vibration analysis (Tranter 1989).

Overall level (r.m.s.) measurements

Peak level detection

Crest factor

Shock pulse \& spike energy

Kurtosis

Demodulation (envelope detection)

Phase

Time waveform

Orbits
Most common vibration measurement in use. Most simple and inexpensive type of measurement. Greatest limitation is the lack of sensitivity and information available in the data. Unless a problem is severe, r.m.s. may not change significantly.

Particularly useful for monitoring the change in the amount of impulsiveness, possibly due to increased bearing damage. This method is not $100 \%$ reliable, as other effects can also increase the peak level of a signal.

The crest factor (sometimes called the impact index) is the ratio of the peak level to the r.m.s. level. This method also has limitations.

Basically a measure of the vibration level at the bearing resonance, usually above $30 \mathrm{kHz}$. Widely used, however, concern has been expressed as the reading can decrease in later stages due to a reduction in impulsiveness, and other conditions, such as turbulence and cavitation in pumps, can give false readings.

Statistical parameter, derived from the statistical moments of the probability density function of the vibration signal. The Kurtosis technique has the major advantage that the calculated value is independent of load or speed variations.

Often the bearing signals are swamped by more dominant low frequency signals. This method, which can be implemented as a Hilbert transform, filters out low frequency signals, leaving a clean signal dominated by the bearing frequencies.

Phase indicates the relative timing between two points. It is used in balancing and is useful when diagnosing imbalance, misalignment, looseness and other cases.

Using an oscilloscope, it is possible to view the waveform of the vibration. Difficult to use in isolation, it can be very helpful tool in combination with others.

Taken using two channel oscilloscope connected to proximity probes. More recently, they have been derived from a pair of frequency spectra. The major benefit is that they show the relative motion of the dominant vibration of the shaft.

Choice of accelerometer is not restricted to measurement in the acceleration mode only, because an acceleration signal can be converted into velocity or displacement with no loss of accuracy. The best mode to be used for measurement is the one that gives a spectrum with little or no slope, as this takes up the least dynamic range in a measuring system. It is found that velocity is the best mode.

A vibration signature, as obtained by the accelerometer or any other transducer, is a time-base signal which may be processed for its overall level, peak level, phase, spike energy etc. Some of the diagnostic indicators can be evaluated by making time-based analyses. Table 1 summarizes these indicators, which can be adopted as useful parameters in trend analysis.

A vibration signature may be a combination of various harmonics, which is obtained by processing the signal through a frequency analyzer. Each part of the frequency is a potential 
Table 2. Common faults and frequencies (Tranter 1989).

\begin{tabular}{|c|c|c|}
\hline Frequency & Possible cause & Comments \\
\hline $1 \times \mathrm{rpm}$ & $\begin{array}{l}\text { Misalignment } \\
\text { or bent shaft } \\
\text { Strain } \\
\text { Looseness } \\
\text { Resonance } \\
\text { Electrical }\end{array}$ & $\begin{array}{l}\text { Steady phase that follows transducer. Can be caused by load } \\
\text { variation, material build-up or pump cavitation } \\
\text { High axial levels, } 180^{\circ} \text { axial phase relation at the shaft ends. Usually } \\
\text { characterized by high } 2 \times \text { rpm } \\
\text { Caused by casing or foundation distortion, or from attached } \\
\text { structures (e.g. piping) } \\
\text { Directional changes with transducer location. Usually high harmonic } \\
\text { content and random phase. } \\
\text { Drops off sharply with change in speed. From attached structures } \\
\text { Broken rotor bar in induction motor. } 2 \times \text { slip frequency sidebands } \\
\text { often produced }\end{array}$ \\
\hline $2 \times \mathrm{rpm}$ & $\begin{array}{l}\text { Misalignment } \\
\text { or bent shaft }\end{array}$ & High levels of axial vibration \\
\hline Harmonics & $\begin{array}{l}\text { Looseness } \\
\text { Rubs }\end{array}$ & $\begin{array}{l}\text { Impulsive or truncated waveform; large number of harmonics } \\
\text { Shaft contacting machine housing }\end{array}$ \\
\hline Sub-rpm & $\begin{array}{l}\text { Oil whirl } \\
\text { Bearing cage }\end{array}$ & $\begin{array}{l}\text { Typically } 0.43-0.48 \text { of } \mathrm{rpm} \text {; unstable phase } \\
\text { Fundamental train }=0.5 \times \mathrm{rps}[1-(\text { ball dia) } /(\text { pitch dial }) \times \operatorname{COS} \\
\text { (contact angle) }]\end{array}$ \\
\hline$N \times \mathrm{rpm}$ & $\begin{array}{l}\text { Gears } \\
\text { Belts } \\
\text { Blades/vanes }\end{array}$ & $\begin{array}{l}\text { Inner race }=0.5 \times \# \text { balls } \times \text { rps }[1+(\text { ball dia }) /(\text { Pitch dia }) \times \operatorname{COS} \\
(\text { contact angle })] \\
\text { Outer race }=0.5 \times \# \text { balls } \times \text { rps }[1 \text {-(ball dia }) /(\text { pitch dia }) \times \operatorname{COS} \\
(\text { contact angle })] \\
\text { Ball defect }=0.5 \times(\text { pitch dia }) /(\text { ball dia }) \times \text { rps }[1 \text {-(ball dia }) /(\text { pitch } \\
\left.\text { dia) } \times \operatorname{COS~(contact~angle~})^{2}\right] \\
\text { Usually modulated by running speed } \\
\text { Gearmesh } \# \text { teeth } \times \text { rpm); usually modulated by running speed } \\
\text { Belt } \times \text { running speed and } 2 \times \text { running speed. } \\
\text { \# Blades } / \text { vanes } \times \text { rpm; usually present in normal machine. } \\
\text { Harmonics usually indicate that a problem exists }\end{array}$ \\
\hline$N \times$ powerline & Electrical & Shorted stator; broken or eccentric rotor \\
\hline Resonance & & $\begin{array}{l}\text { Several sources, including shaft, casing, foundation and attached } \\
\text { structures. Frequency is proportional to stiffness and inversely } \\
\text { proportional to mass. Run-up tests and modal analysis are useful } \\
\text { in this area }\end{array}$ \\
\hline
\end{tabular}

indicator of the machine condition. Spectrum analysis is the most powerful technique for diagnostic study. The underlying principle is that each operating component of the machine generates identifiable frequencies. Thus, changes in the vibration level at a given frequency can be related directly to the concerned machine components. Based on the basic knowledge associated with the nature of machine operation and the principles enunciated in $\S 2$, one should be able to calculate the frequencies consequent to the impending faults. In the literature, charts supplying this information are available. Table 2 is one such chart giving a summary of fault frequencies and the relevant faults (Tranter 1989).

Sometimes, a change in the individual frequency component does not bring about any significant change in the overall vibration level. Figure 2 illustrates one such case, where not much change in the overall vibration level was observed, but a steady increase in vibration level at specific bearing frequencies over several months was noticed, indicating 


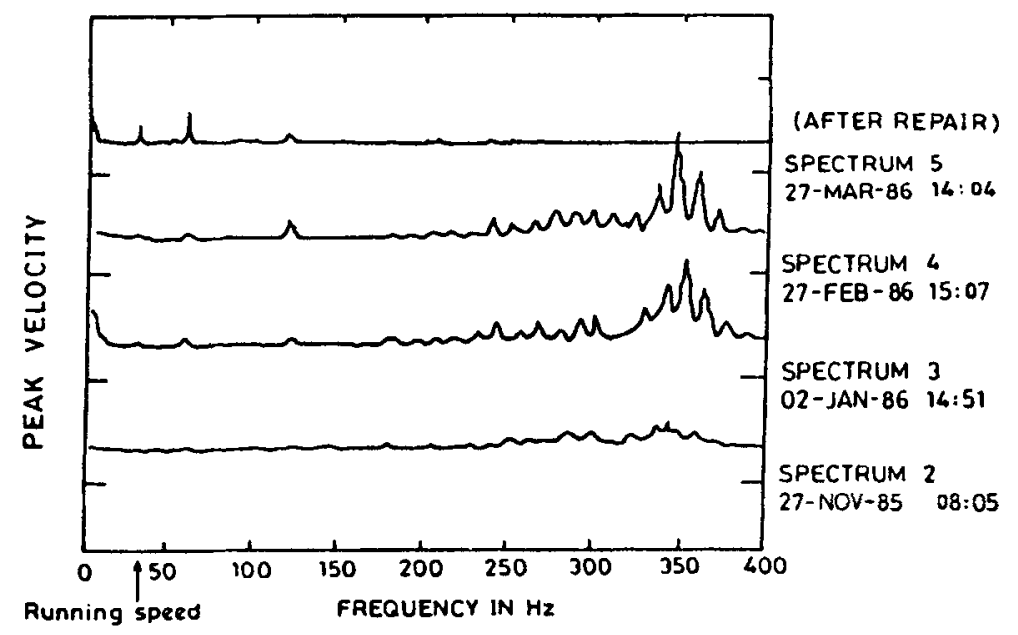

Figure 2. High pressure water pump bearing failure.

that the bearing condition was steadily deteriorating. In this particular case, balls and races were found badly spalled and the cage was fractured at two places.

There are a number of indices derived from the frequency spectrum. They are very useful parameters for trend analysis. Table 3 lists these parameters and describes their diagnostic characteristics.

For trend analysis to be performed, a reference base signature of the machine in good condition is needed. To ascertain whether the machine is in good condition, three or four machine signatures are taken at weekly intervals under the same operating condition. If no change is noted in the vibration spectrum, the machine's internal condition must be reasonably stable and the machine can be considered in good health. The first spectrum can be used as a base line spectrum for trend analysis.

Trend monitoring strategy is adopted where it becomes difficult to generate acceptable vibration levels. The underlying idea in trend monitoring is that the rate of deterioration in vibration level of the machine increases rapidly near breakdown. The vibration signature is recorded regularly, and the values for the chosen indices as listed in tables 1 and 3 are determined, and the trend noted. The lead time before the degradation reaches breakdown is one of the main advantages.of the trend monitoring. During the lead period maintenance actions are planned.

\section{Vibration monitoring programmes}

The monitoring programmes can be classified into three levels of sophistication. This is reflected in the speed with which they can detect the faults and provide information for locating them.

The simplest system consists of an accelerometer and a vibration meter (figure $3 \mathrm{a}$ ). It measures the vibration level over a specific wide-frequency range. Measurements are compared with the established reference values for each machine. If such reference values are not generated for each machine, they can be taken from the general standards like 
Table 3. Frequency based vibration analysis (Tranter 1989).

\begin{tabular}{ll}
\hline Spectrum & $\begin{array}{l}\text { Derived from the vibration waveform by performing a 'fast } \\
\text { Fourier transform' (FFT). Given that the running speed of the } \\
\text { machine is directly proportional to the frequency measured, } \\
\text { it is possible to relate peaks in the spectrum to the machine } \\
\text { components } \\
\text { A waterfall plot (also known as spectral map and cascade plot) } \\
\text { is a three-dimensional representation of spectra, usually with } \\
\text { time as the third dimension } \\
\text { Waterfall plot } \\
\text { The FFT of the logarithm of the power spectrum. Used to high- } \\
\text { light periodicities in the spectrum. Useful in bearing and gear- } \\
\text { box analysis } \\
\text { By mathematically subtracting two spectra, changes in level } \\
\text { are easily identified. Fault frequency analysis is performed to } \\
\text { relate the frequencies to the machine components. Does not } \\
\text { cope well with running speed changes } \\
\text { Difference spectra } \\
\text { The rms of the difference between the current spectrum and the } \\
\text { baseline, and the current spectrum and the previous spectrum, } \\
\text { have both been found to be useful trending parameters } \\
\text { Another method of trending the difference between vibration } \\
\text { Matched filter }\end{array} \quad \begin{array}{l}\text { Anectra. Found to be a reliable trending parameter. Quantifies } \\
\text { the differences between spectra by summing the squares of the } \\
\text { corresponding amplitude ratios in the spectra and taking the } \\
\text { logarithm of the result }\end{array}$ \\
\hline
\end{tabular}

VDI 2056. This is the cheapest system and the operator does not require much training. Machine condition is evaluated in the field from minimum data. The system however has some limitation. If the change in vibration level is from more than one source, the method cannot diagnose the actual source of trouble. For diagnosing the source of trouble some instruments are required to perform the time-based analysis to obtain the parameters, as mentioned in table 1 . Some of these facilities are provided in the vibration meter. In the specific case of rolling element bearings, and where vibrations from other sources do not dominate, early warning of bearing deterioration can be obtained. The meter is switched to measure simultaneously both the peak and rms vibration levels up to $10 \mathrm{kHz}$. At the earlier stage of fault development in the bearings, very little change in the rms level is noted, although the peak level increases significantly. By evaluating the crest factor (peak/rms ratio) many rolling element bearing faults can be detected at an earlier stage.

Fault detection at an earlier stage together with diagnosis is also possible, when using a system which can perform frequency analysis. Full frequency analysis and spectrum plot-out are done on the spot for each monitoring point. The system is shown in figure $3 \mathrm{~b}$. Current spectra are compared manually with the recorded reference spectra to reveal telltale increases in the level of individual frequency components. Reference (baseline) spectra are recorded for each monitoring point and transferred to transparent sheets. Subsequent spectra are placed under the reference sheets, where any difference will be immediately apparent. As the levels of certain frequency components begin to grow, they are plotted on a level versus time chart, so that failure trends can be predicted. This enables the fault to be diagnosed, spare parts to be ordered and repair to be scheduled conveniently. Some 


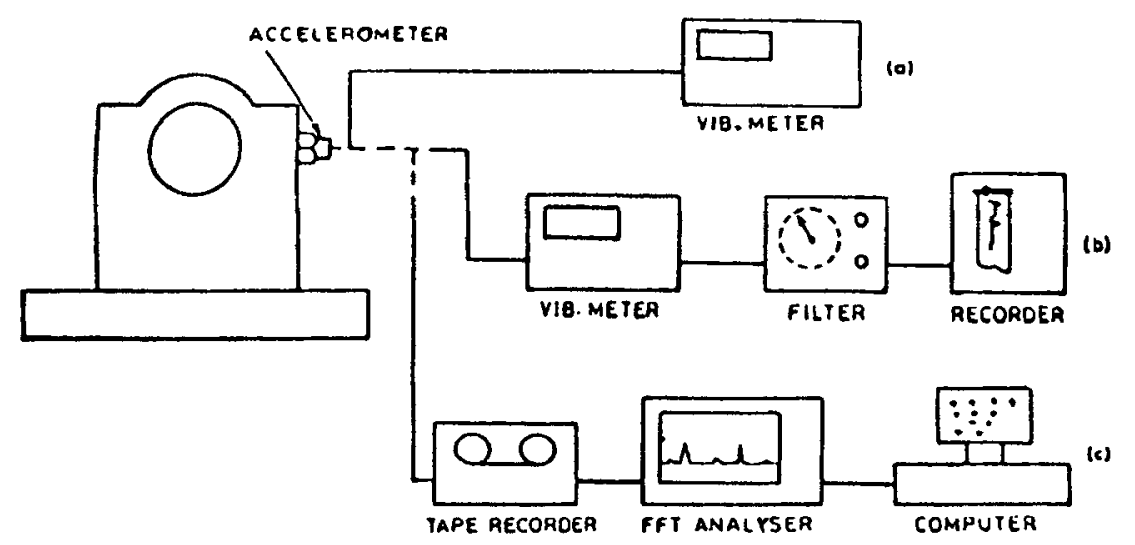

Figure 3. Vibration monitoring systems. (a) Simple system for vibration measurement; (b) system for frequency analysis; (c) system for computer-aided off-line trend monitoring.

users perform simple wide band monitoring on a regular basis and employ the frequency analyzer when sufficient changes in the vibration level are noted. While analysis at this stage will aid diagnosis of the developing fault, the early warning and trend benefits of regular analysis are not available in this case.

As the number of monitoring points increases, a computer-aided spectrum comparison system will be the most economical solution. Vibration signatures from each machine are collected on an instrumentation tape recorder. They are analyzed on a real-time frequency analyzer in the office, and the current spectra are compared with the baseline spectra under semi-automatic control from a desk-top computer coupled to the analyzer (figure 3c). Advanced programmes aid fault diagnosis and trend monitoring. Narrow-band frequency analysis on a linear frequency scale as provided by the FFT analyzer gives excellent display of harmonic and side-band frequency components, a particularly valuable information for diagnostic purposes. Where the analyzer includes a zoom facility, any part of the spectrum can be expanded to further enhance the details of individual components.

\section{Permanent monitoring system}

Such a vibration monitoring system is permanently installed on a specific machine and continuously watches its condition. Its function is to give immediate warning of any sudden changes in the condition of expensive non-duplicated machinery, whose continuous operation is vital to the production process. Faulty conditions are detected immediately or within minutes of occurrence and trigger alert or alarm signals in the plant control room, so that appropriate measures can be taken before a catastrophic failure occurs. These systems are widely used in the power generation and petrochemical industries on turbines, feed pumps, gas compressors etc. A typical system is shown in figure 4.

In a basic system, a single module may continuously monitor vibration over a single specified frequency range. If preset limits are breached (e.g. minimum, alert and alarm), the system can trigger visual or audible alarms. Alternative options can provide for up to three individual frequency bands to be monitored simultaneously. Coverage of many 


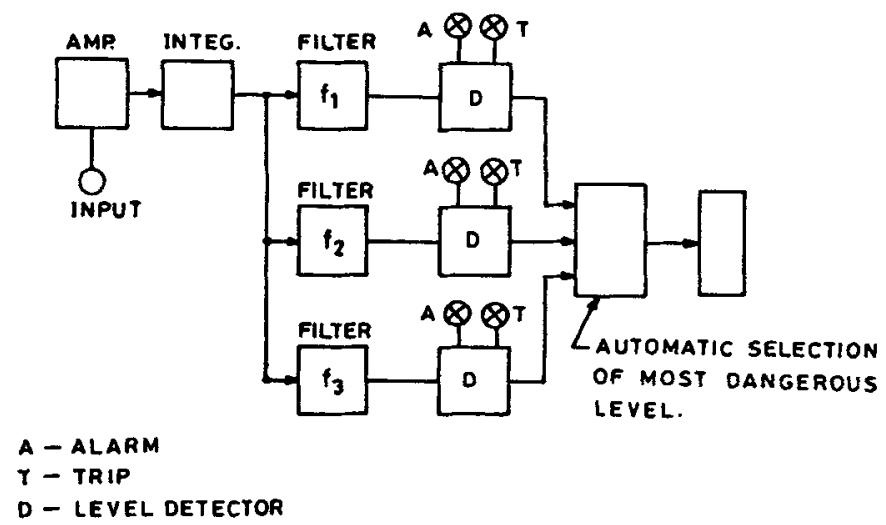

Figure 4. Permanent monitoring system.

monitoring points can be provided by a multiplexer connected to the input of a single monitoring module. A multiplexer continuously steps through the chosen channels, dwelling at each channel for a preselected period before automatically moving on to the next. Several multiplexers can be connected to obtain the economic multichannel systems. Spectrum analyzers can be coupled to the monitoring system when fault diagnosis is required and, in the most sophisticated systems, computer-controlled fault detection is applied automatically to all monitoring points.

Main requirements for all permanent monitoring systems are extremely high operational reliability, long-term stability and immunity to adverse environmental conditions and irregularities which can cause false alarms. To safeguard from false alarm, these systems are sometimes provided with an automatic test system, so that the plant operator can immediately check whether the instrumentation is functioning correctly in the event of an alarm.

\section{Future trends in vibration monitoring and fault diagnosis}

Future trends, which are visible in the present day practice, are given below.

\subsection{Permanently installed monitoring devices}

Machines and equipment with built-in monitoring devices are increasing day by day. Generating sets, steam and gas turbines, special purpose machine tools and production machines, refinery equipment are just some of the examples. It is foreseen that through increased and improved vendor relations in the near future, critical equipment will have installed monitors at the insistence of the customer or through the intention of the vendor. This trend is surely going to result in better reliability, availability and maintainability of the machinery.

\subsection{Computers for data processing and management}

Trend analysis is the best way of diagnosing incipient machine trouble. It provides sufficient lead time for carrying out a maintenance operation at a convenient time, but generates 
enormous amounts of data to be reduced and logged, which becomes difficult if done manually. Further, it is true that the use of a number of parameters and techniques in combination will give the best indication of machine condition. This means that large amounts of data must be collected, analyzed and interpreted. Computers can help in a big way to manage such huge amounts of data and store useful information after data reduction. This information can be retrieved in no time for trend analysis. Use of computers is gradually increasing. In some cases, monitored data are manually fed to the computer, while in others it is automatically done with the use of multiplexers and A/D interfacing. The computer gives out alert reports, trend graphs and diagnostic information.

\subsection{Expert systems}

Fault tracing on the basis of monitored and analysed data is not always straightforward. It needs guidance from the experts who, based on their knowledge and experience, are able to pin-point the source of trouble. An expert, besides possessing knowledge of the subject, also has the ability to think in a progressively logical manner, which is a positive advantage in the world of problem-solving associated with plant and machinery faults. Perhaps this is where the area of 'artificial intelligence' has something to offer.

An expert system consists of a knowledge-base, an inference engine and a user interface. The knowledge-base contains a set of rules and facts that an expert system uses to solve a particular problem. The rules describe the relationship between the machinery problems and the corresponding symptoms. The inference engine contains control mechanisms to control the operation of the system and to infer information from the knowledge-base by using the rules to reason about the facts. The user interface enables communication between the user and the computer.

\section{Case studies}

Three case studies are presented to show how the vibration signature could help in diagnosing the source of troubles.

\subsection{Dryer foundation vibrations}

In this case study (Gupta et al 1986), the problem was of excessive vibrations at the foundation block near the discharge end, and the objective was to determine the cause of these vibrations.

The dryer consists of a shell of $20 \mathrm{~m}$ length and $2.5 \mathrm{~m}$ diameter. It is supported on two foundation blocks, $12 \mathrm{~m}$ apart, through two pairs of rollers. A schematic view of the shell on the foundation block nearer to the discharge end is shown in figure 5. The dryer is meant for drying polypropylene (PP) granules. It is driven at a speed of $3.5 \mathrm{rpm}$ by an electric motor through reduction gears and a pinion. The complete drive unit is mounted on the foundation block nearer to the intake end of the dryer. The PP granules passing through the dryer get dried by the steam passing through a number of tubes arranged along the shell length and near its circumference. A number of hammers are arranged along the 


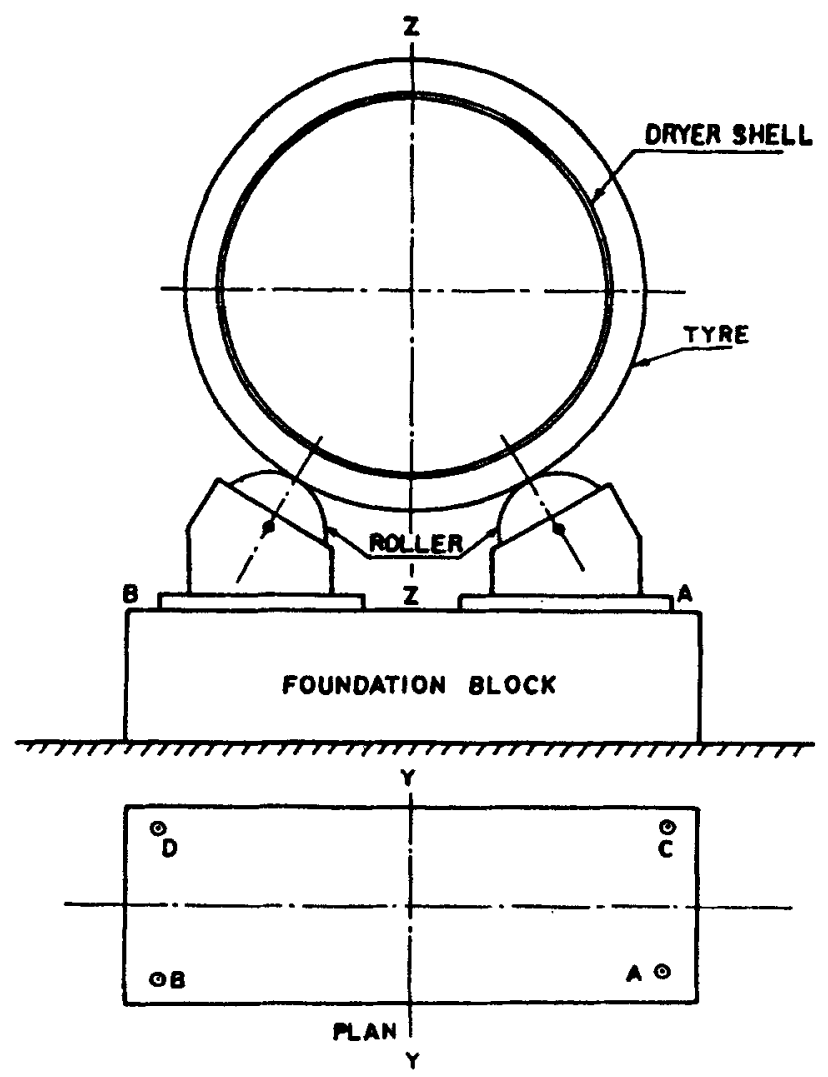

Figure 5. Schematic of the sectional view of the dryer on foundation and location of measuring points.

circumference of the shell and near the intake end. These hammers fall on the shell surface under gravity during shell rotation and thus tapping the shell surface, so that PP material should not stick to the surface and choke the passage.

Vibration measurements were conducted on the foundation block. A time-base signal as recorded is shown in figure 6 , and the corresponding frequency spectrum is shown in figure 7. The time-base record corresponded to a narrow-band signal showing the dominance of 6 to $7 \mathrm{~Hz}$ vibration. Of course, the amplitudes varied in random fashion. The frequency spectrum also confirmed the presence of 5.2, 6.0 and $6.5 \mathrm{~Hz}$ harmonics. A simple theoretical analysis revealed that these frequencies were nothing but the natural frequencies of the foundation block in three modes. Further, it was noticed in the time-base record that there was repetition of the similar pattern of the signal after every $4.0 \mathrm{~s}$, corresponding to a frequency of $0.25 \mathrm{~Hz}$, which happened to be the rotational speed of the roller. Zones of these repetition are marked in figure 6 . Hence, it may be inferred that some irregularity on the roller surface caused this repeated phenomenon.

From the foregoing discussion it was concluded that the foundation block was getting excited in its natural modes. This was possible if it was excited by a wide-band process encompassing the frequencies of the natural modes. It was realized that the wide-band process arose from the interaction of the pits formed on the tyre and roller surfaces. 

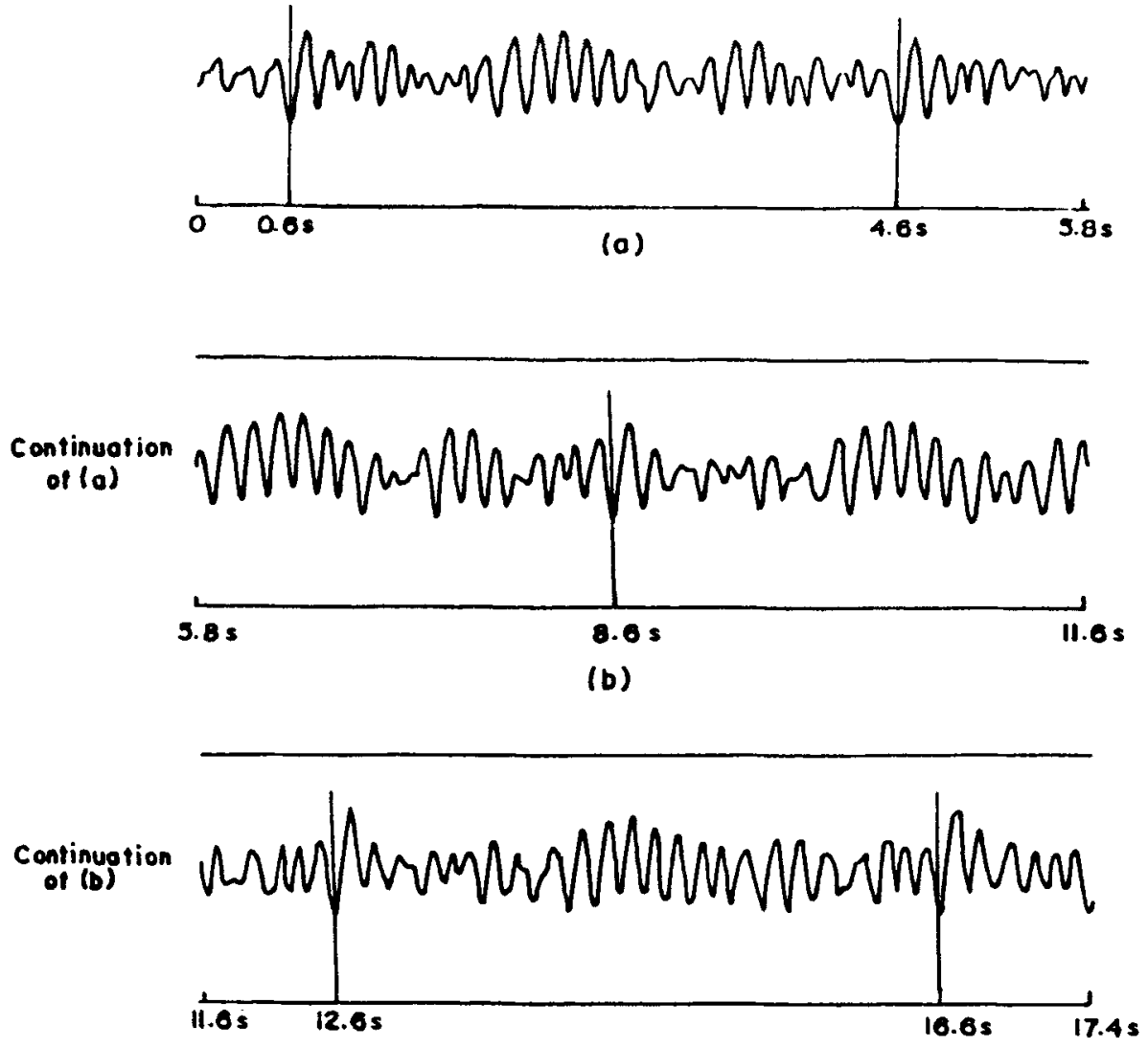

(c)

Figure 6. Time-based record of the vibration at the foundation.

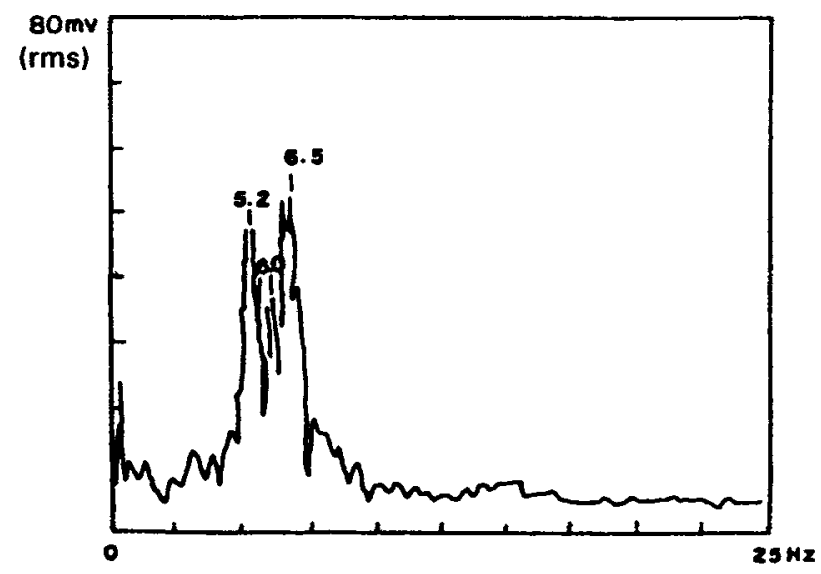

Figure 7. Frequency spectrum of the foundation vibration. 
These pits might have been formed in course of time due to excessive stresses and lack of lubrication. The pits were of different sizes and spread randomly over the surfaces. During operation of the dryer, if pits of minute sizes fell on the track of contact, the foundation had low level vibration, while in case of big pits, there was excessive vibration.

The following recommendation was made.

"Pit formations are because of excessive contact stresses and lack of lubrication. Contact stresses can be reduced by increasing the area of contact. Sufficient lubrication can be provided by dipping the rollers in the oil bath, so that their surfaces are well smeared with oil before coming in contact with the tyre. If pit formations still persist, they should be repaired during the shut down period by pouring welding material and then grinding the spots."

The company did adopt the above measures and did not face any more problem of excessive vibrations at the foundation block.

\subsection{Excessive vibrations of the piping connecting booster pump $(B P)$ and boiler feed pump (BFP) (Gupta et al 1988)}

While commissioning a super thermal power unit $(500 \mathrm{MW})$ at a certain power station, vibrations of very large amplitude were observed in the piping connecting the BP and the BFP under certain conditions of operation, viz. safety valve blow-out operation. The region of these severe vibrations is marked in the characteristic curve of the BFP (figure 8). We were required to detect the cause of the trouble and also suggest a possible solution to the problem.

Figure 9 shows the relative positions of BP, BFP and the piping layout. Both BP and BFP are installed on the ground floor of the Power House, while the deaerator tank (DT) is situated at a height of about $26.5 \mathrm{~m}$, thus providing a positive suction head of $30.5 \mathrm{~m}$ of liquid column to the BP. The water from DT goes to the BP through a barrel-type strainer having a mesh size of $0.2 \mathrm{~mm}$. The BP is driven by an electric motor at a constant speed of $1493 \mathrm{rpm}$. The discharge from the BP is connected to the BFP through another barrel-type strainer with a mesh size of $0.5 \mathrm{~mm}$. The BFP is driven by the same electric motor through gears and hydraulic coupling. Its speed can be controlled from 1490 to $5905 \mathrm{rpm}$ by changing the position of the scoop in the hydraulic coupling. The discharge pipe of the BFP is mounted with a recirculation valve, which directs the excess flow to the recirculation piping leading to the DT.

We decided to record the vibrations of the piping at suitable locations under conditions of severe and non-severe vibration and to analyse these records in the laboratory for the frequency contents. We thought that a comparison of their vibration spectra would provide a clue to the identification of the source of trouble.

Figure 9 shows the four locations at which vibration signatures were recorded in the three directions. Signatures were also recorded at the BP suction pressure tapping (location 5 in figure 9), in order to have an idea of the frequencies of pressure pulsations in the water. Vibration measurements were carried out on two occasions. On both occasions, so-called severe vibration conditions could not be achieved. Vibration signatures were analysed for the frequency spectrum. The major frequency components present are listed in table 4 . 


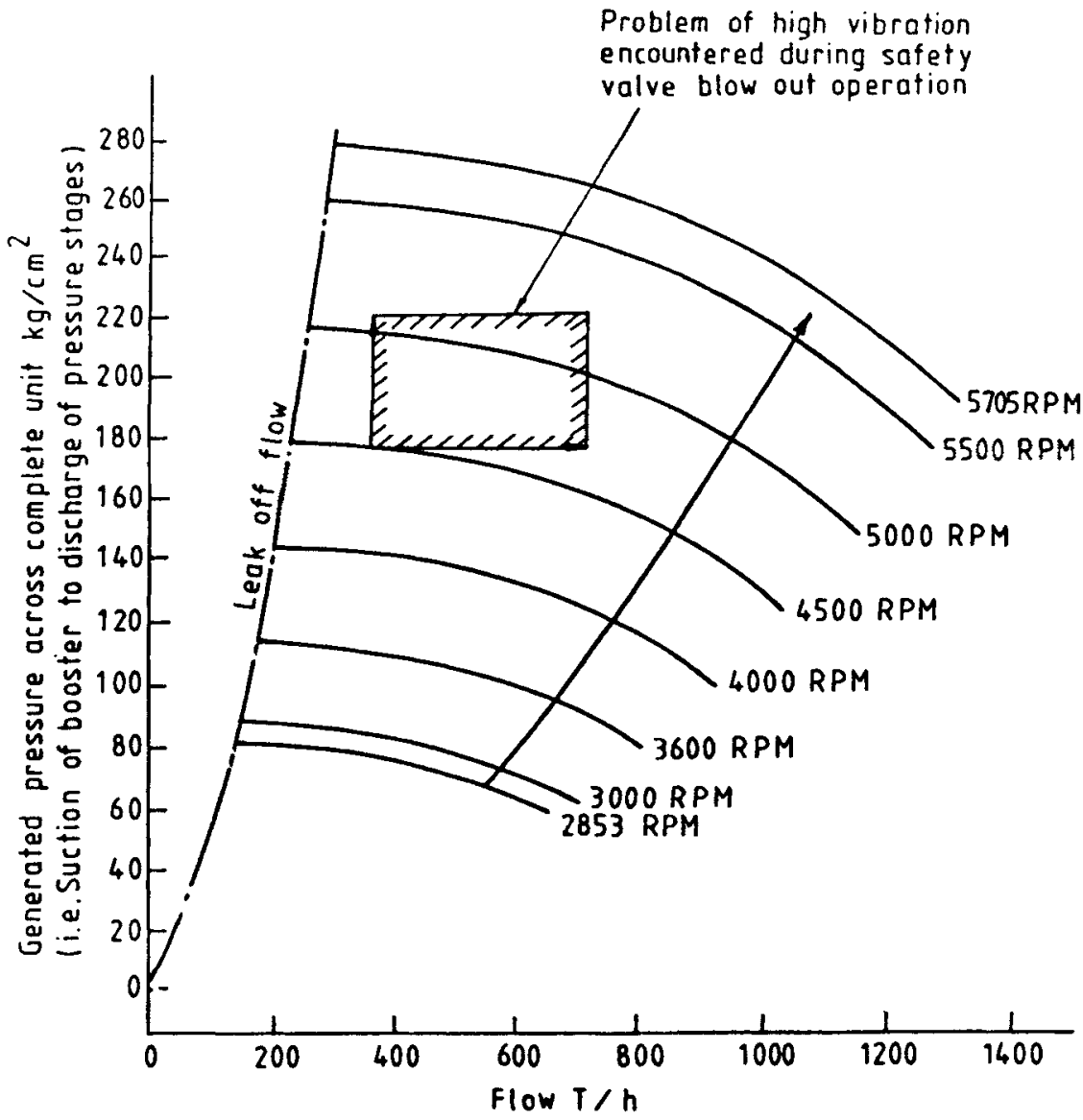

Figure 8. Motor-driven BFP performance curve on cold water (s.g. 1.0).

Further, the natural frequencies of the piping structure were determined by the rap test, and were in the range of 2.5 to $3.0 \mathrm{~Hz}$.

It was concluded that the severe vibrations of the interconnecting piping were due to resonance. Based on the experimental results and also on the experience of other research workers on centrifugal pumps as used in powerplants, the possibility of the following causes is mooted. A logical discussion is also included while deliberating on these causes.

(i) Presence of pressure pulsations even at non-severe conditions of operation has been identified but did not cause large piping vibrations because of non-coincidence of the excitation frequencies with the natural frequencies of the piping. Pressure pulsations are as a result of internal recirculation. It is well-known that centrigugal pumps are prone to internal recirculation at reduced flows (compared to rated flow). Consequences of internal recirculation are noisy operation and pressure pulsations (hydraulic surges) of low frequencies $(1-8 \mathrm{~Hz})$ causing pipeline vibration. It was noted that with increase in flow rate, pressure pulsation intensity was reduced, thus confirming the above reason for pressure pulsations. Pressure pulsations due to internal recirculation can be avoided by, 


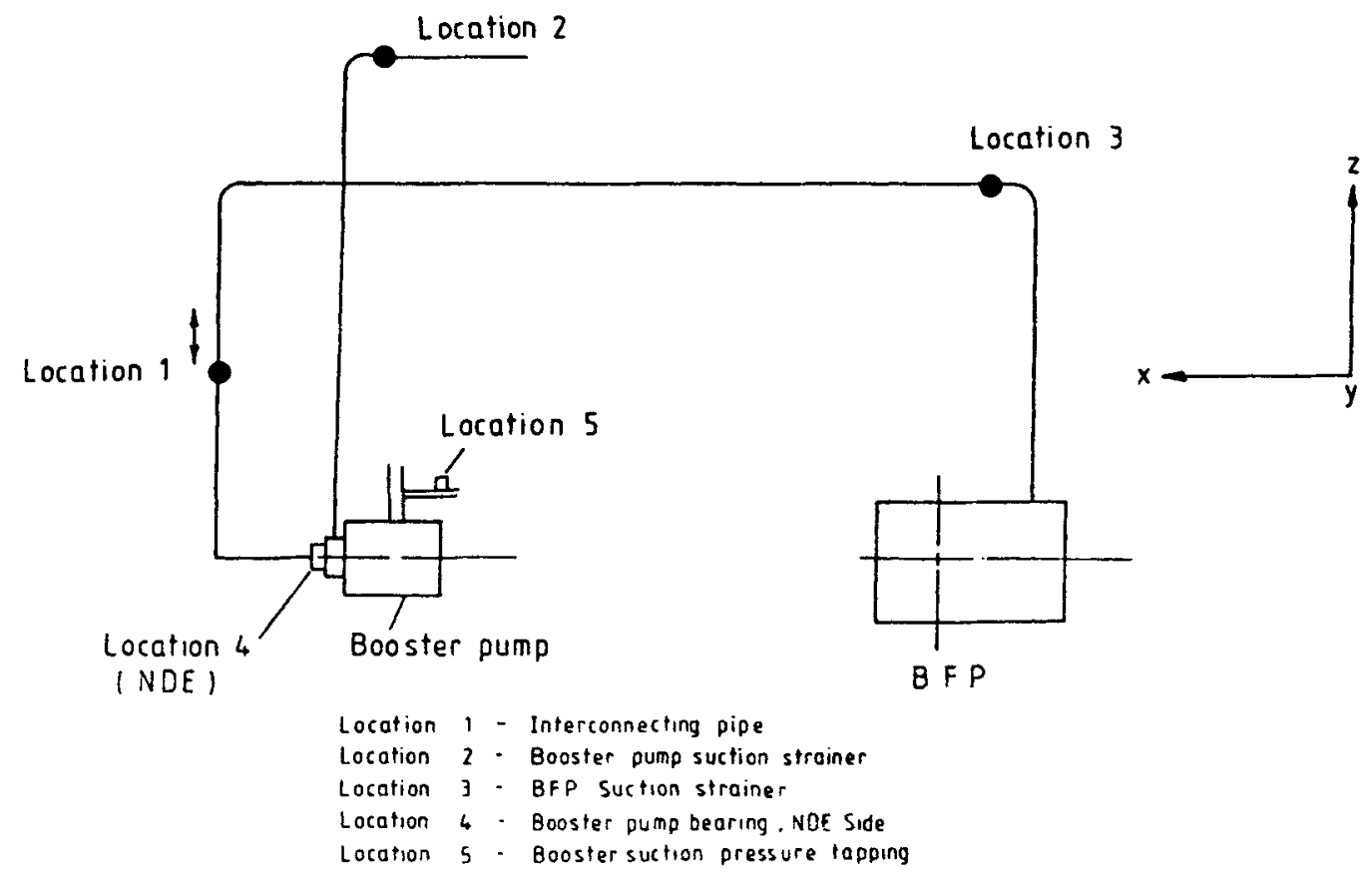

Figure 9. Booster pump, BFP and piping layout with measuring points location.

(a) reduction of pump inlet eye area by providing suitable inserts;

(b) running the pump at the rated flow capacity so as not to result in internal recirculation and deviating the excess flow at the delivery end through the recirculation pipeline, i.e. increasing the capacity of the recirculation valve and associated piping at the outlet of the BFP. This solution has worked very well in a somewhat similar situation (Pattabiraman et al 1986).

(ii) Referring to figure 8, severe vibrations of the piping have occurred at BFP discharge pressures of $176 \mathrm{~kg} / \mathrm{cm}^{2}$ and flow rates of $350 \mathrm{t} / \mathrm{h}$ onwards. These conditions are needed to make the safety valve operative but at the discharge pressure of $168 \mathrm{~kg} / \mathrm{cm}^{2}$ piping vibrations are reported to be of low level. It seems that floating of the safety

Table 4. Frequency components (in hertz) of vibration signatures.

\begin{tabular}{|c|c|c|c|c|c|c|c|c|c|c|c|}
\hline \multicolumn{3}{|c|}{ Location 1} & \multicolumn{3}{|c|}{ Location 2} & \multicolumn{3}{|c|}{ Location 3} & \multicolumn{2}{|c|}{ Location 4} & \multirow[t]{2}{*}{ Location 5} \\
\hline$\overline{\mathrm{V}}$ & $\mathrm{T}$ & A & V & $T$ & A & $\mathrm{V}$ & $T$ & $\bar{A}$ & $\overline{\mathrm{H}}$ & $\mathrm{V}$ & \\
\hline - & - & 1.64 & - & 1.7 & - & - & - & - & - & 2.0 & 1.9 \\
\hline 2.4 & 2.4 & 2.4 & - & 2.4 & 2.5 & 2.9 & 2.6 & 2.6 & 2.8 & - & - \\
\hline 3.4 & 3.3 & 3.3 & - & - & - & 3.4 & 3.4 & - & - & - & - \\
\hline 5.7 & 5.8 & 5.8 & 6.1 & 6.0 & 6.0 & 5.8 & 5.8 & 6.0 & 6.0 & - & 5.9 \\
\hline 6.9 & - & 7.1 & - & - & - & - & - & 7.3 & 6.6 & - & - \\
\hline 8.1 & 8.5 & 8.5 & - & - & - & 8.5 & 8.5 & 8.5 & 8.4 & - & - \\
\hline 9.5 & 9.7 & 9.5 & 9.2 & 9.2 & 9.0 & 9.4 & 9.4 & 9.7 & - & 9.4 & 9.6 \\
\hline
\end{tabular}

Abbreviations: A - axial, $\mathrm{H}$ - horizontal, $\mathrm{T}$ - trans, V - vertical. 
valve might have induced low frequency pulsations of the range of $2-3 \mathrm{~Hz}$ in the fluid column from boiler to pump and pump to deaerator tank causing resonance of the piping system. Simpson \& Tramschek (1974) have conducted a study on pulsations in power station feed-pump systems and reported that fluid column frequencies can be as low as $1.5 \mathrm{~Hz}$, and any low frequency excitation may set in pressure fluctuations in the column.

\subsection{Vibration problem at the non-driven end bearing of a generator of the gas based powerplant (Gupta \& Yadava 1991)}

Very high vibration level of $2 \times N$ frequency at the non-driven end (NDE) bearing of a generator was reported. It was required to identify the cause of this high vibration level.

Vibration measurements were carried out at the DE and NDE bearings of the generator in all the three directions and also for two load settings, viz. 61 and $82 \mathrm{MW}$. This was done to see whether the electrical load had any influence on the vibration level. Spectral analysis was performed on the recorded signatures, and some useful information from this analysis is presented in table 5 .

In this table vibration levels in millimetres per second at frequencies $1 \times N, 2 \times N$ and $4 \times N$ ( $N$ being rotational speed of the rotor) are presented for loads of 61 and $82 \mathrm{MW}$. Dominance of the second harmonic vibration over the first harmonic vibration is clearly visible, particularly in the vertical direction at the NDE bearing, but the level is not affected much by the change in electrical load except at the NDE bearing in the horizontal direction. The frequency components which are greatly affected by the change of electrical load are underlined. These are the $4 \times N$ component in the vertical direction at both the DE and NDE bearings, and the $2 \times N$ component in the horizontal direction only at the NDE bearing. This information may help in tracing the cause of trouble by making use of the following knowledge-base.

The generator is a two-pole machine, so any defect producing a change in air gap between the pole and stator leads to an unbalanced magnetic pull, whose intensity increases with the flux, which in turn varies directly with the load. The unbalanced magnetic pull occurs twice in one rotation of the rotor, and gives rise to vibrations of $2 \times N$ frequency and

Table 5. Vibration levels at frequencies $1 \times N, 2 \times N$ and $4 \times N(N=3000 \mathrm{rpm})$.

\begin{tabular}{|c|c|c|c|c|c|}
\hline \multirow{3}{*}{$\begin{array}{l}\text { Location } \\
\text { direction }\end{array}$} & \multirow[b]{3}{*}{ Frequency } & \multicolumn{4}{|c|}{ Vibration level (mm/s) } \\
\hline & & \multicolumn{2}{|c|}{$\overline{\mathrm{DE}}$ bearing load } & \multicolumn{2}{|c|}{ NDE bearing load } \\
\hline & & $61 \mathrm{MW}$ & $82 \mathrm{MW}$ & $\overline{61 \mathrm{MW}}$ & $82 \mathrm{MW}$ \\
\hline Vertical & $\begin{array}{l}1 \times N \\
2 \times N \\
4 \times N\end{array}$ & $\begin{array}{l}0.56 \\
3.55 \\
0.11 \\
\end{array}$ & $\begin{array}{l}0.62 \\
4.12 \\
0.27 \\
\end{array}$ & $\begin{array}{l}0.67 \\
8.42 \\
0.17 \\
\end{array}$ & $\begin{array}{l}0.68 \\
8.52 \\
0.94 \\
\end{array}$ \\
\hline Axial & $\begin{array}{l}1 \times N \\
2 \times N \\
4 \times N\end{array}$ & $\begin{array}{l}0.54 \\
3.13 \\
0.05\end{array}$ & $\begin{array}{l}0.55 \\
3.16 \\
0.07\end{array}$ & $\begin{array}{l}1.27 \\
2.99 \\
0.50\end{array}$ & $\begin{array}{l}1.20 \\
2.79 \\
0.59\end{array}$ \\
\hline Horizontal & $\begin{array}{l}1 \times N \\
2 \times N \\
4 \times N\end{array}$ & $\begin{array}{l}1.50 \\
5.44 \\
0.09\end{array}$ & $\begin{array}{l}1.51 \\
5.19 \\
0.07\end{array}$ & $\begin{array}{l}1.55 \\
0.13 \\
0.30\end{array}$ & $\begin{array}{l}1.76 \\
0.35 \\
0.25\end{array}$ \\
\hline
\end{tabular}


multiples of this frequency in the stator body or bearing support. The magnitude of the higher harmonics depends on the shape of the unbalanced magnetic pull. Further, if there are two defects located $45^{\circ}$ from the horizontal plane and on either side of the vertical axis, the net dominant unbalanced pull will be in the vertical direction and its frequency is $4 \times N$. The $4 \times N$ component in the horizontal direction gets moderated with the increase in load because of the opposing action. The enormous increase in the $2 \times N$ vibration level with the electrical load in the horizontal direction at NDE bearing suggests the presence of a defect in the stator at the level of its axis and near the NDE bearing. Similarly, the enormous increase in vibration level of the $4 \times N$ harmonic in the vertical direction both at $\mathrm{DE}$ and NDE bearings suggests the presence of two defects located $45^{\circ}$ from the horizontal plane on either side of the vertical axis and situated somewhere along the length of the stator. It may be noted that the $4 \times N$ harmonic in the horizontal direction is somewhat moderated with the increase in electrical load.

It was recommended that the generator be opened to inspect the stator for any defect causing a change in the air gap, and on doing this it was found that the cover strips near the NDE bearing were absent. These were put back and the problem of high $2 \times N$ vibrations was eliminated.

\section{Concluding remarks}

Vibration is a very effective tool for diagnosing many mechanical defects. It however needs expert knowledge and experience for fault-tracing. When vibrations are used for condition monitoring, it is always advisable to start with simple instrumentation and before applying the technique to plant or machinery maintenance, the economical viability must be assessed. It is envisaged that in the near future the use of computers in handling the large amounts of monitored data and reducing them to usable information formats will expand. The tendency to use expert systems for fault diagnosis will also increse. There will be attempts to develop expert systems dedicated to a class of specific plants and machinery.

\section{References}

Collacott R A 1973 Mechanical fault diagnosis (London: Chapman and Hall)

Collacott R A 1977 Fault diagnosis and condition monitoring (London: Chapman and Hall)

Gupta K N 1986 Vibration monitoring - an overview. Proc. Workshop on Diagnostic Maintenance, New Delhi, pp 45-62

Gupta K N 1990 Vibration monitoring - state-of-the-art and future trends. Proc. State-of-Art and Future Vision Seminar on Condition Monitoring, New Delhi, pp II/1-16

Gupta K N, Yadava G S 1991 Vibration problem at NDE bearing of the generator at Anta Gas Project. Report submitted to NTPC, New Delhi

Gupta K N, Asnani N T, Nakra B C, Tandon N 1986 Cause analysis of dryer foundation vibrations at IPCL Complex, Baroda. Proc. Workshop on Performance Assurance in Machinery, Ahmedabad, pp MD 1-8 
Gupta K N, Gupta K, Reddy P V 1988 Diagnosis of BFP inter-connecting piping vibration through signature analysis. Proc. 17th National Convention on Maintenance Management for Higher Productivity, IIPE, Jamshedpur, pp III/2/1-18

Pattabiraman J, Srinivasan R, Bhattacharjee D K 1986 Vibration studies on a suction piping of a boiler feed pump. Symp. on Vibration Problems in Nuclear Power Stations, Bombay

Simpson H C, Tramschek A B 1974 Pulsations in power station feed pump systems. Proc. Inst. Mech. Engineers, Conf. on Component Interaction in Fluid Flow Systems, London

Tranter J 1989 The fundamentals of, and the application of computers to condition monitoring and predictive maintenance. Proc. Int. Congress on Condition Monitoring and Diagnostic Engineering (COMADEM 1989), pp 372-377 